\title{
Programmed instruction revisited: a study on teaching stereochemistry
}

\author{
N. Izzet Kurbanoglua , Yavuz Taskesenligil ${ }^{b}$ and Mustafa Sozbilir ${ }^{b}$ \\ ${ }^{a}$ Sakarya University, Hendek Education Faculty, Department of Primary Science \\ Education, Sakarya, Turkey \\ ${ }^{b}$ Ataturk University, Kazim Karabekir Education Faculty, Department of Secondary \\ Science and Mathematics Education, 25240-Erzurum, Turkey \\ e-mail: sozbilir@atauni.edu.tr
}

Received 3 February 2005, accepted 15 December 2005

\begin{abstract}
This study is aimed at comparing the success of programmed instruction with the conventional teaching approach on teaching stereochemistry, and whether gender has any effect on student success. Forty chemistry teacher trainees attending the same class in the Department of Chemistry Education in a large state university in eastern Turkey were the subjects of the study. Of the forty trainees twenty were selected as the experimental group and the other twenty as the control group. The study was implemented in a total of sixteen lecture hours (each $50 \mathrm{~min}$ ) in four weeks (four lecture hours per week). The subject, stereochemistry in organic chemistry, was taught to the experimental group by the researcher through 'programmed instruction' and the control group was taught by the course lecturer through traditional teaching. The data collection tools were: Stereochemistry Achievement Test (SAT), programmed stages (frames), and the views of the students. An ANCOVA (Analysis of CoVariance) showed that there was a statistically significant difference between programmed instruction and conventional teaching approach on the success level of students' learning in stereochemistry. In addition, it was found that female students were more successful than their male counterparts in the experimental group. The findings suggest that programmed learning could be considered as a better alternative to conventional lecturing in teaching stereochemistry. [Chem. Educ. Res. Pract., 2006, 7 (1), 13-21]
\end{abstract}

Keywords: chemical education research, university (tertiary) level, stereochemistry teaching, programmed instruction-based teaching and learning, student-centred learning.

\section{Introduction}

Higher education courses in chemistry at universities and other institutions have, perhaps, mainly been centred on the lecturer's comprehension of a topic rather than that of the student. Nevertheless, in the past four decades student-centred learning has aroused considerable interest at all levels of education systems, including universities (Hinchliffe, 1982). Several alternative methods, based on students being at the centre of control, have been suggested since the days of Aristotle. These have come down to us mainly in the form of the tutorial/seminar system. During the past decades, personalized (i.e. individual) instruction by experiment or even fully autonomous learning has been developed for teaching in all areas (Boland, 1977).

One feature of many of these alternative methods is that they are self-paced. Students plan their own time schedule, usually by receiving and completing only one assignment at any one time, and thereby raise their achievement in a subsequent test performance. However, there 
are studies that opposed the self-pacing approach because it offers little improvement on traditional lectures (Cassidy, 1973; Reiser and Sullivan, 1977). Another beneficial feature claimed for student-centred methods is that they allow more time to be spent by the teacher tutoring individual or very small groups of students. This has been claimed, in particular, by the advocates of computer-assisted learning (Hinchliffe, 1982).

Programmed learning is one of the better-known methods of student-centred learning, and its potential advantages have been fully discussed (Skinner, 1958; Young, 1961; Young 1966; Beard, 1973; Boland, 1977; Hinchliffe, 1982). Programmed instruction was among the first in historical significance for instructional developments and analytical processes, important to instructional design. The programmed instruction movement extended the use of printed selfinstruction to all school subject areas to adult and vocational education as well. Later, as the technology developed, other media, such as radio, television video and computer, came into use. Computer-assisted instruction, which both tests students' abilities and marks their progress, may supplement classroom activity or help students to develop ideas and skills independently.

The first teaching machine was invented by Pressey (1927), but it was not until the 1950s that practical methods of programming were developed. Programmed instruction was introduced in 1954 by B. F. Skinner of Harvard (Skinner, 1954), and much of the system is based on his theory of the nature of learning. As programming technology developed so did the range of teaching machines and other programmed instruction materials. Programs have been devised for the teaching of spelling, reading, arithmetic, foreign languages, physics, psychology, and a number of other subjects. Some programs are linear in concept, allowing advancement only in a particular order as the correct answer is given. Others are branching, giving additional information at the appropriate level whether a correct or incorrect answer is given (Young, 1966).

Although there has been considerable controversy regarding the merits of programmed instruction as the sole method of teaching, many educators agree that it can contribute to more efficient classroom procedures and supplement conventional teaching methods. Programmed instruction enables students to work individually, calling for active participation of the learner. In some areas, such as industry and the armed services, programmed instruction is often used to train personnel. A primary feature of programmed instruction is that information needed by the student is presented in an order that is most helpful to him/her, particularly if he/she is a beginner in the field. Comprehensive knowledge of a topic is ordered in textbooks in terms that are appropriate to the subject, rather than to the students. It is clear, therefore, that programmed instruction should be an adjunct; it cannot replace textbooks and reference books in university education (Young, 1966).

Teaching organic chemistry at the introductory level has made it obvious to the teachers that understanding stereochemistry can be difficult and sometimes traumatic for students. Stereochemistry is frequently a source of confusion when students are first exposed to it, and unfortunately, this feeling may linger even after repeated exposure (Bowen and Bodner, 1991; Bodner, 2003). Visualizing the three-dimensional aspects of molecules and their relationships to other molecules is difficult (Brand, 1987). When dealing with principles that are particularly difficult to visualize or conceptualize, such as stereochemistry, teaching aids and mnemonic devices have been invaluable in the learning process. Realizing that all teaching aids and devices cannot be presented by the instructor in the lecture, these methods can be passed on most efficiently through teaching assistants and tutors due to the one-on-one nature of student contact time. Often these devices help individual students make a connection between the new material and their own experiences and prior knowledge base. For that reason, a variety of methods have been established that cater to the respective strengths of 
each individual. These methods vary from mathematical approaches to two-dimensional Fischer projection techniques to the three-dimensional models (Barta and Stille, 1994).

Although several different approaches and computer-assisted learning materials have been developed throughout the developed countries, there has been no study carried out in Turkey on students' learning difficulties in stereochemistry, and also, no programmed instruction materials developed on stereochemistry in Turkish. Therefore, this study is an attempt to develop a programmed instruction material that could be used in teaching introductory Organic Chemistry courses in Turkey.

This study is aimed at comparing the success of programmed instruction with the conventional teaching approach on teaching stereochemistry, and whether gender has any effect on student success. Gender effect was included as a factor potentially affecting learning in stereochemistry, as suggested in the literature (see Boothroyd and Chapman, 1987). Hence, two null hypotheses tested in this study were worded as follows. (a) There is no significant main effect of gender on the students' mean scores taught through programmed instruction and conventional teaching approaches, and (b) there is no significant main effect of the teaching approach on students' mean scores taught through programmed instruction and conventional teaching approaches.

\section{Methodology}

\section{Sample}

The sample of the study was composed of forty second year undergraduate students (chemistry teacher trainees; twenty male and twenty female) enrolled to Organic Chemistry-I course ( 4 hours per week and 14 weeks in a semester) at the Department of Chemistry Education of a large state university in Eastern Turkey at the first semester of 2002-3 academic year. Before dividing the students into groups, an achievement test specifically developed for this study, was applied as pre-test. Since the students' scores showed homogeneity, they were divided into two groups as experimental and control groups by only considering the equality of the gender distribution. An independent sample t-test was carried out, and no statistically significant difference was found between the students' pre-test scores in terms of gender $(t=1.97$; $p>0.05$; see Table 1$)$. The number of students in the groups and the mean scores in the pre-test could be seen at Table 3 .

Table 1. Pre-test means, std. dev. and std. error means, according to gender.

\begin{tabular}{cccccc}
\hline & Gender & N & Mean & Std. Dev. & Std. Error Mean \\
\hline \multirow{2}{*}{ Pre-test } & Male & 20 & 20.9 & 7.8 & 1.7 \\
& Female & 20 & 16.9 & 4.6 & 1.0 \\
\hline
\end{tabular}

$(\mathrm{t}=1.97 ; \mathrm{p}>0.05)$

\section{Materials and Procedure}

Stereochemistry Achievement Test (SAT): An achievement test, composed of 12 openended questions, each having sub-questions, was developed using the literature and textbooks. Questions in the SAT were mainly at knowledge/comprehension levels according to Bloom's taxonomy. The validity of the test was achieved by consulting five organic chemistry professors. With respect to the reliability, SAT was administered to a group of forty-seven students who took Organic Chemistry-I course the year before. The Kuder-Richardson formula was used for determining the reliability of SAT and reliability coefficient was found as $(\alpha=0.62)$. This level of reliability coefficient for an achievement test indicates that the test could be considered satisfactorily reliable (McMillan and Schumacher, 2001; p.243). A sample question can be seen in Figure 1. 
Figure 1. A sample question used in SAT.

Question 2. Examine the following formulas and select those pairs that satisfy the following conditions: Be sure to enter two letters (and only two) in each answer box. Please note that there may be more than one possible answer for the second and fourth questions.

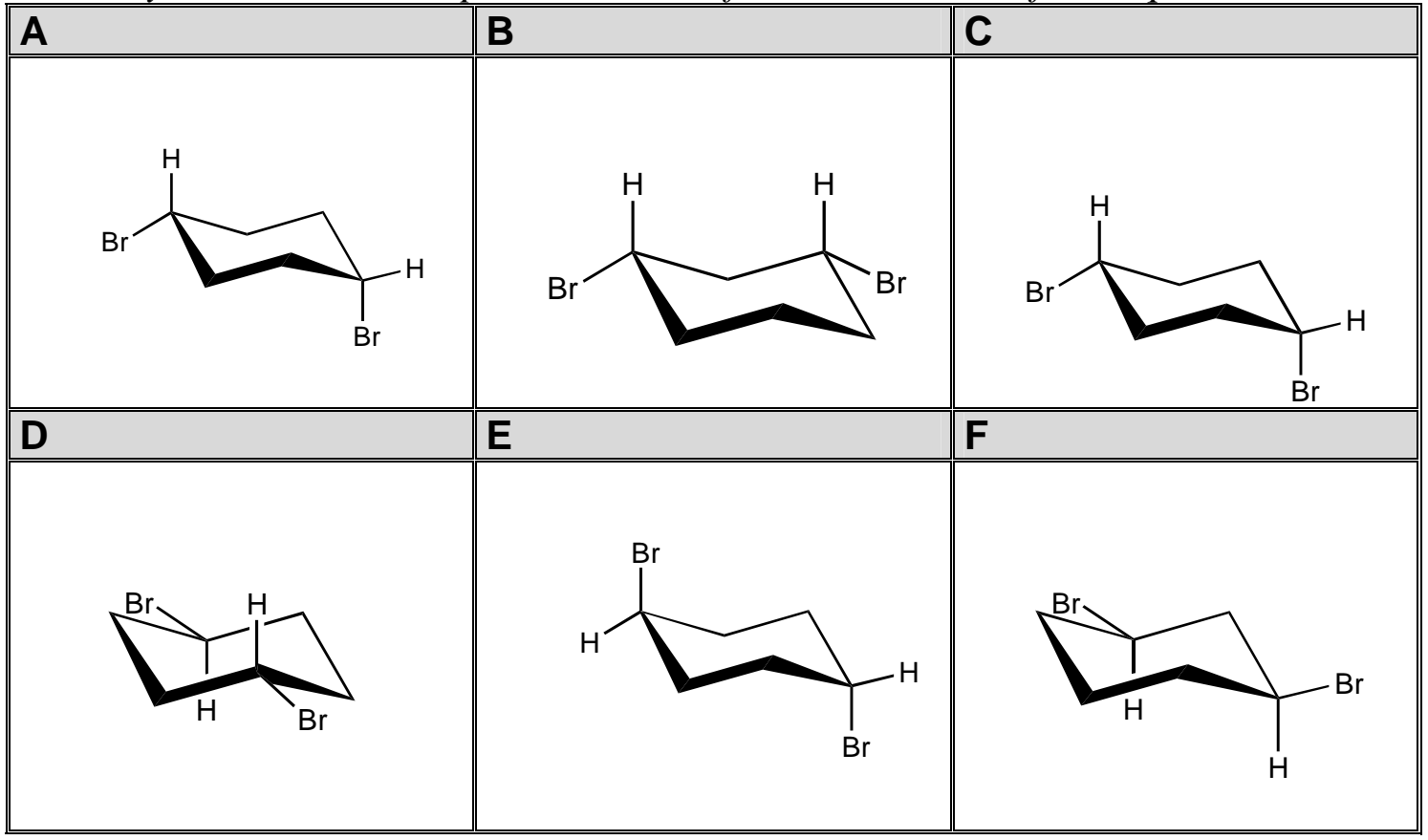

-1- Which are identical in all respects?

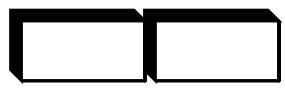

2- Which are configurational isomers?

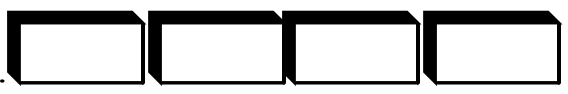

-3- Which are conformational isomers

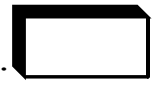

4- Which are structural isomers?

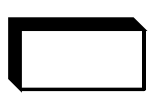

Programmed Frames: Programmed instruction is based on a series of very small steps, called frames. Each frame contains some information and a statement with a blank that the student fills in. The student then uncovers the correct answer before going on to the next frame. If the student's answer was correct it is positively reinforced by progress to the next frame; if not, the student immediately sees the correct answer. Each frame may introduce either a new idea or repeat material covered earlier. The lessons start from the student's initial knowledge and in small steps proceed to a final learning goal. Because of active student participation, small steps, immediate feedback and reinforcement, programmed learning can be very effective. All students work through the same sequence (Anderson and Fretzin, 2004). The answer to the question in a frame is given in the following frame. In this study linear sequencing was employed. A total of sixty-five frames were prepared, covering all stereochemistry concepts and principles at introductory level. A sample of frames could be seen in Figure 2. 
Figure 2. A sample frame of programmed steps
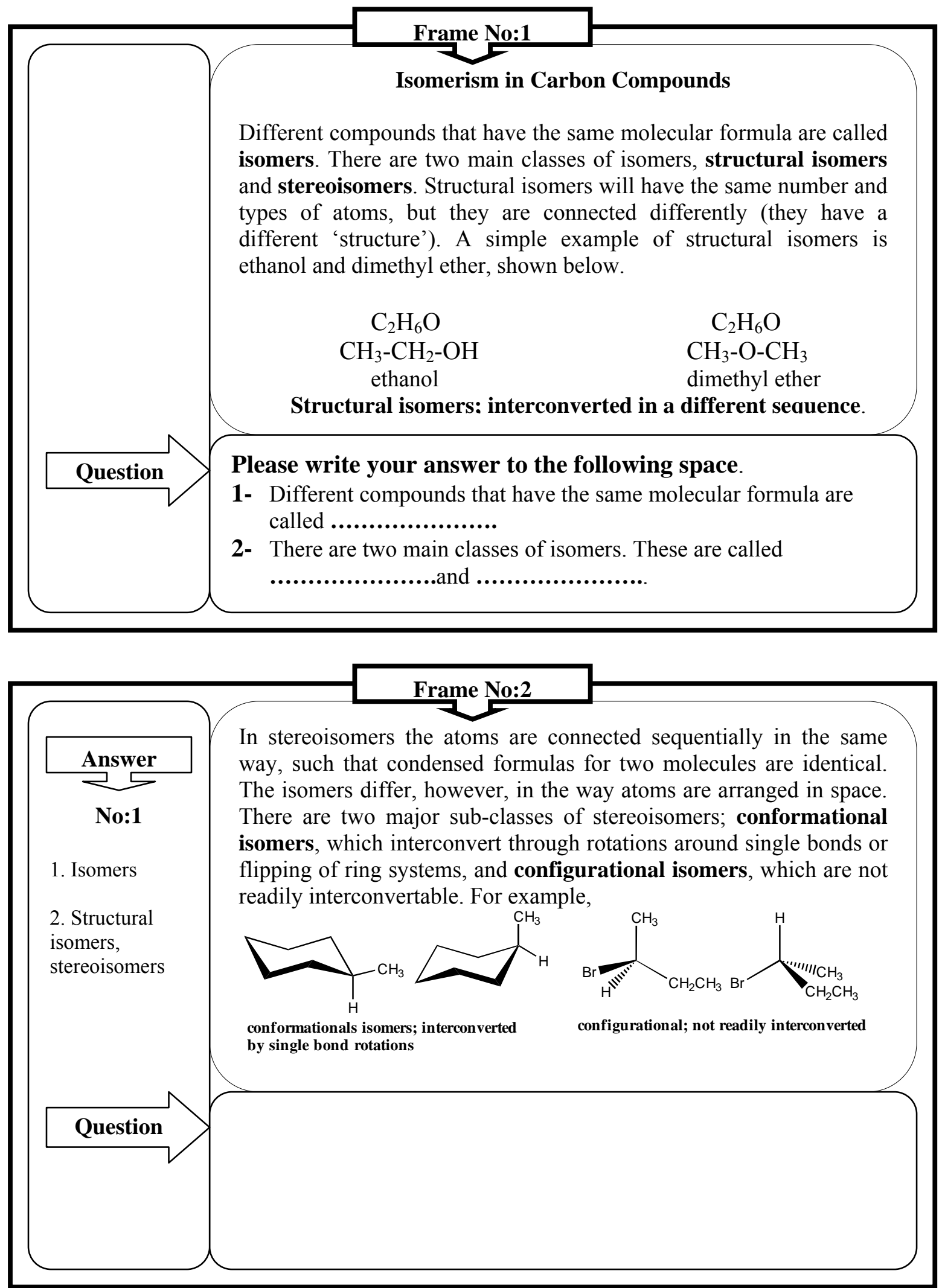
Procedure: Treatment was completed in a total of sixteen lecture hours (a short hour) in four weeks (four lecture hours per week). The control group was taught by a lecturer from the department with over twenty years of experience in teaching Organic Chemistry. The students were guided, as in previous years, by using a conventional teaching approach. This was mainly delivered by lecturing, and molecular models were used by the lecturer. In the experimental group, where programmed instruction was administered, the teaching responsibility was taken by one of the researchers. There was no lecturing in the experimental group. Each student was given a frame according to the sequence shown in Table 2 (the control group also followed the same graded sequence). When a student completed the given frame, he/she was presented with the next frame. The rate of progress depended on the students. In this way the speed of the students ranged from 3 to 5 frames in each lecture hour. The researcher took mainly a tutoring role rather than that of an instructor. He guided the students in the use the frames and helped them in places where students needed explanations and extra help. In this way, all the students were kept active, and they were involved in the learning process. During this process neither additional information was given nor extra problems solved beyond those which were given in the frames. However, students were free to get information outside of class hours. Each student had the chance of learning about stereochemistry at his/her own pace. When the treatment was completed, both the control and experimental groups were given the SAT as a post-test. Moreover, students' views about the programmed instruction were gathered from the experimental group. For this purpose, students were given a blank sheet and they were asked to write their views about the treatment. They were asked not to write their names on the sheets in order to ensure confidentiality.

Table 2. Distributions of the topics covered within stereochemistry according to the weeks in the control and experimental groups.

\begin{tabular}{ll}
\hline \multirow{3}{*}{$\mathbf{1}^{\text {st }}$ Week } & - Isomerism \\
& - Structural isomers \\
& - Stereoisomerism \\
\hline \multirow{2}{*}{$\mathbf{2}^{\text {nd }}$ Week } & - Conformational isomerism \\
\hline \multirow{3}{*}{$\mathbf{3}^{\text {rd }}$ Week } & - Diasteromers (Geometric isomerism in alkenes) \\
& - Enantiomers (Chirality and a chiral carbon) \\
& (Determination of the configuration of enantiomers: R and S system, Fischer projections \\
\multirow{2}{*}{$\mathbf{4}^{\text {th }}$ Week } & - Diastereomers containing stereogenic centers \\
& - Diastereomers with chiral carbons (meso compounds) \\
& Isomers of disubstitued cyclocompounds
\end{tabular}

Data analysis: Data was analyzed by using SPSS10.0 (Statistical Package for Social Sciences). The significance level was set to 0.05 since it is the most used value in educational studies. In other words, the probability of rejecting the true null hypothesis (probability of making Type I error) was set to 0.05 a priori to hypothesis testing. In order to find out the effect of the treatment (programmed instruction) on students' learning of stereochemistry ANCOVA (Analysis of Co-variance) was used, since it gives the pre-test as true co-variant rather than a focus of interest in itself (Dugard and Todman, 1995). 


\section{Results}

Descriptive statistics related to total scores of pre-test and post-test were categorized according to groups and gender, and are presented in Table 3.

Table 3. Descriptive statistics for mean scores of pre-test and post-test according to the groups and

\begin{tabular}{llllcc}
\hline Group & Treatment & Gender & N & Means of Pre-Test & Means of Post-Test \\
\hline \multirow{3}{*}{ Experimental } & \multirow{2}{*}{ Programmed } & Male & 10 & 20.8 & 64.7 \\
& Instruction & Female & 10 & 18.2 & 76.4 \\
& & Total & $\mathbf{2 0}$ & $\mathbf{1 9 . 5}$ & $\mathbf{7 0 . 5}$ \\
& & Male & 10 & 21.1 & 42.9 \\
& Conventional & Female & 10 & 15.8 & 50.8 \\
& Instruction & Total & $\mathbf{2 0}$ & $\mathbf{1 8 . 4}$ & $\mathbf{4 6 . 9}$ \\
\hline
\end{tabular}

As shown in Table 3, mean scores (70.5) of the students in the experimental group were higher than that of in the control group (46.7) in the post-test, while their scores were similar in the pre-test (19.5 and 18.4 for experimental and controls groups, respectively).

Table 3 also indicates that while female students scores were slightly lower than that of their male counterparts in the pre-test, they were significantly better than their male counterparts in the post-test (see Table 3 for the mean scores). Independent sample t-test indicates that there was no statistically significant difference between them in pre-test; however, ANCOVA results in Table 4 show that females performed better through programmed instruction than males $[F(1,39)=10.8 ; p<0.05]$, (see Table 5 for the calculated means of groups and gender for post-test).

Table 4. ANCOVA Results (Tests of between-subjects effects dependent variable: post-test)

\begin{tabular}{lcccc}
\hline Source & df & Mean Square & $\boldsymbol{F}$ & Significance \\
\hline Corrected Model & 3 & 2429.9 & 18.4 & 0.000 \\
Intercept & 1 & 7997.6 & 60.5 & 0.000 \\
Group (Control -Experimental) & 1 & 5213.3 & 39.4 & $0.000^{*}$ \\
Gender (Male-Female) & 1 & 1428.8 & 10.8 & $0.002^{*}$ \\
Pre-test & 1 & 743.4 & 5.6 & $0.023^{*}$ \\
Error & 36 & 132.3 & & \\
Total & 40 & & & \\
Corrected Total & 39 & & & \\
a $\mathrm{R}^{2}=0.605$ (adjusted $\left.\mathrm{R}^{2}=0.572\right)$ & & & & \\
$*$ Significant at 0.05 level & & & &
\end{tabular}

Table 5. Calculated means of groups and gender. (Dependent Variable: Post-test)

\begin{tabular}{ccccc}
\hline & Mean & Std. Error & \multicolumn{2}{c}{ 95\% Confidence Interval } \\
\cline { 2 - 5 } Group & & & Lower Bound & Upper Bound \\
\hline Experimental & 70.2 & 2.6 & 64.9 & 75.4 \\
Control & 47.2 & 2.6 & 42.0 & 52.5 \\
Gender & & & & \\
Male & 52.4 & 2.6 & 47.1 & 57.8 \\
Female & 64.9 & 2.6 & 59.6 & 70.3 \\
\hline
\end{tabular}


This result refutes the first hypothesis that there is no significant main effect of gender on the students' mean scores taught through programmed instruction and conventional teaching approaches. This result contradicts the findings of Boothroyd and Chapman (1987) in which male students were more successful than their female counterparts. In our study, female students' better performance through programmed instruction-based learning perhaps could be explained by their interest in the study and also by their greater self-discipline. It is known that attitude and motivation are important factors in learning. During the treatment, female students liked and showed greater interest in the study than the male students, therefore it was an expected result that female students performed better. In addition, since the programmed instruction is cumulative, attendance at the course is one of the most important factors affecting the achievement. Some of the male students were absent from some sessions of the treatment, and they had to study more frames in the following lectures, therefore this might have affected their performance in the course.

ANCOVA results shown in Table 4 confirm the effect of programmed instruction on students' learning of stereochemistry $[F(1,39)=39.4 ; p<0.05]$. This result also refutes the second research hypothesis that there is no significant main effect of teaching approach on students' mean scores taught through programmed instruction and conventional teaching approaches. The ANCOVA results also suggest that there was a significant main effect of pretest factor on students' performance at post-test $[F(1,39)=5.6 ; p<0.05]$. This result confirms that it was a correct action taking pre-test scores as a co-variant.

With respect to the students' views of the programmed instruction, there was an overwhelming student satisfaction according to the student survey. These results suggested that students liked the structure of the programmed instruction following a graded sequence in small steps so that students can work according to their own learning speed, having no time restrictions, and being able to use frames given to them as a supplementary material at home. All these views are in agreement with the previous studies (Powell, 1963; Boothroyd and Chapman, 1987).

\section{Discussion and implications}

Using both pre-test and post-test results, it was shown statistically that while there was no difference between the groups prior to intervention, the experimental group performed significantly better than the control group after the treatment. This is consistent with the claims made for programmed instruction based on student impression (Hinchliffe, 1982). The limited but objective results in this paper suggest that substantially self-paced programmed learning is a better technique than the conventional lecturing in stereochemistry. Another important aspect is that programmed instruction forces student active participation in the teaching-learning process. It shifts the responsibility for learning back to the student, where it should be. Because it provides for a self-paced, logical sequence of small steps, and immediate confirmation or correction, it helps to overcome the wide spread of abilities and interest among university chemistry students (Powell, 1963).

However, the field remains wide open for further, carefully documented work using computer-assisted learning materials, especially in Turkish. The next stage of this study is going to be the development of a computer program by using the frames in this study to apply to a wide range of students from different departments. It would also be desirable to conduct research on different areas of chemistry at the undergraduate level. Further research would include comparing the developed computer programs with programs that use more conventional techniques. But even more important than such research is the further refinement of these techniques. 


\section{References}

Anderson T. and Fretzin, L., (2004), Programmed instruction, http://Irs.ed.uiuc.edu/students/fretzin/epl1q2programmed.htm, (accessed on July 2004).

Barta N.S. and Stille, J.R., (1994), Grasping the concepts of stereochemistry. Journal of Chemical Education, 71, 20-23.

Beard R., (1973), Teaching and learning in higher education ( $3^{\text {rd }}$ Edition), Penguin, London (see especially page 161).

Bodner G.M., (2003) Problem solving: the difference between what we do and what we tell students to do, University Chemistry Education, 7, 37-45.

Boland R.G.A., (1977) Design of autonomous group learning. Programmed learning and educational technology, 14, 233.

Boothroyd R.A. and Chapman, D.W., (1987) Gender differences and achievement in Liberian primary school children, International Journal of Educational Development, 7, 99-105.

Bowen C.W. and Bodner G.M., (1991) Problem-solving process used by graduate students while solving task in organic synthesis, International Journal of Science Education, 13, 143-158.

Brand D.J., (1987) Molecular structure and chirality, Journal of Chemical Education, 64, 1035-1038.

Cassidy P.E., (1973) Programmed self-paced instruction in freshman chemistry, Symposium on selfpaced instruction, University of Wisconsin.

Dugard P. and Todman J., (1995), Analysis of pre-test - post-test control group designs in educational research, Educational Psychology, 15, 181-198.

Hinchliffe P.R., (1982), An experiment in programmed learning in physical chemistry for metallurgist, Journal of Chemical Education, 59, 588-592.

McMillan J.H and Schumacher S., (2001) Research in education: a conceptual introduction (5th Edition), Longman, London.

Powell V.P., (1963), Programmed instruction in high school chemistry, Journal of Chemical Education, 40, 23-24.

Pressey S.L., (1927), A machine for automatic teaching of drill material, School and Society, 23, 549552.

Reiser R.A. and Sullivan H.J., (1977), Effects of self-pacing and instructor-pacing in a P.S.I. Course, Journal of Educational Research, 71, 8-11.

Skinner B.F., (1954), The science of learning and the art of teaching, Harvard Educational Review, 24, 86-97.

Skinner, B.F. (1958), Teaching machines, Science, 128, 969-977.

Young J.A., (1961), Programmed instruction in chemistry - an invitation to participate, Journal of Chemical Education, 38, 463-465.

Young J.A., (1966), Programmed instruction in chemistry - a summary review, Journal of Chemical Education, 43, 275-278. 